\title{
A PATH ANALYSIS ON THE FACTORS ASSOCIATED WITH STUNTING IN CHILDREN UNDER FIVE IN THE BORDER AREA OF WEST KALIMANTAN
}

\author{
Eny Indriyani'), Yulia Lanti Retno Dewi ${ }^{2)}$, Harsono Salimo3) \\ ${ }^{1)}$ Masters Program in Public Health, Universitas Sebelas Maret \\ 2)Department of Nutrition, Faculty of medicine, Universitas Sebelas Maret \\ 3)Department of Pediatrics, Dr. Moewardi Hospital, Surakarta
}

\begin{abstract}
Background: Stunting is a form of nutritional deficiency that is closely related to the delayed growth and development of children. It is a chronic linear growth failure due to long-term malnutrition. In 2010, it is estimated that 171 million children (167 million in developing countries) were stunted. Globally, childhood stunting decreased from $39.7 \%$ (95\% CI 38.1, 41.4) in 1990 to $26.7 \%$ (95\% CI $24.8,28.7$ ) in 2010. This trend is expected to reach $21.8 \%$ (95\% CI 19.8, 23.8), or 142 million, in 2020. This study aimed to examine the biopsychosocial factors associated with stunting in children under five in West Kalimantan.

Subjects and Method: This was a case-control study conducted at West Kalimantan. A sample of 200 children under five consisting of 100 stunting children and 100 normal children was selected for this study by fixed disease sampling. The dependent variable was stunting. The independent variables were birth length, maternal education, family income, maternal nutritional intake, maternal middle-upper arm circumference (MUAC), child nutritional intake, and number of children. The data were collected by questionnaire. Path analysis was employed for data analysis.

Results: The risk of stunting increased with child nutritional intake less than recommended nutritional allowance $(\mathrm{b}=1.61,95 \% \mathrm{CI}=0.86$ to $2.36 ; \mathrm{p}<0.001)$, birth length $<48 \mathrm{~cm}(\mathrm{~b}=2.13 ; 95 \% \mathrm{CI}=0.95$ to $3.31 ; \mathrm{p}<0.001)$, and low current maternal education $(b=1.96 ; 95 \% \mathrm{CI}=1.21$ to $2.72 ; \mathrm{p}<0.001)$. The risk of stunting was indirectly and significantly influenced by family income during gestation, number of children, maternal height, maternal MUAC, family support, maternal education during gestation, and maternal nutrition intake during gestation.

Conclusion: The risk of stunting increases with child nutritional intake less than recommended nutritional allowance, birth length $<48 \mathrm{~cm}$, and low current maternal education. The risk of stunting is indirectly and significantly influenced by family income during gestation, number of children, maternal height, maternal MUAC, family support, maternal education during gestation, and maternal nutrition intake during gestation.
\end{abstract}

Keywords: stunting, biopsychosocial factors, gestational period

\section{Correspondence:}

Eny Indriyani. Masters Program in Public Health, Universitas Sebelas Maret, Jl. Ir. Sutami 36 A, Surakarta, Indonesia. Email: zubair.alhafizh@yahoo.com. Mobile: +6282158338438 . 